\title{
Frases célebres do Fausto: um desafio para a tradução
}

\author{
Tinka Reichmann ${ }^{1}$
}

\begin{abstract}
The topic of this paper is to analyse the relation between dicta and translation. I will therefore discuss the origin and the main aspects of the German expression "geflügelte Worte". Afterwards I will present Portuguese translations of some quotations of Goethe's Faust in order to illustrate their structural and semantic complexity and therefore the special challenge for translation. At the end I will show that those quotations are a frequent rhetorical means of newspapers and advertising and briefly comment possibilities of translation.
\end{abstract}

Keywords: Faust, Goethe, quotation, dictum, translation

Resumo: Neste trabalho pretendo analisar a relação entre frases célebres e a tradução. Inicialmente discutirei a origem e as particularidades do termo "Geflügelte Worte“ em alemão. A seguir apresentarei traduções para o português de frases célebres muito conhecidas do Fausto de Goethe, a fim de ilustrar a complexidade estrutural e semântica das mesmas e, conseqüentemente, o especial desafio que elas representam para a tradução. Ao final, mostrarei que frases célebres alteradas são um recurso estilístico freqüente da linguagem jornalística e publicitária e tecerei alguns breves comentários sobre como lidar com este fenômeno na tradução.

Palavras-chave: Fausto, Goethe, frase célebre, sentença notável, citação, tradução

Zusammenfassung: In diesem Aufsatz wird der Zusammenhang zwischen geflügelten Worten und Übersetzung beleuchtet und die Besonderheiten der geflügelten Worte erläutert. Anschließend werden einige portugiesische Übersetzungen bekannter geflügelter Worte aus Goethes Faust herangezogen, um deren strukturelle und semantische Vielfalt und daher auch die besondere Herausforderung an die Übersetzung zu illustrieren. Zum Schluss wird dargestellt, dass abgeänderte geflügelte Worte ein geläufiges Stilmittel der Journalismus- und Werbesprache sind und kurz aufgezeigt, welche übersetzerischen Lösungen hierfür gefunden werden können.

Stichwörter: Faust, Goethe, geflügelte Worte, Übersetzung

\section{Introdução}

Já o título deste artigo permite-nos adentrar diretamente ao cerne do tema, pois ele engloba a problemática de encontrar uma tradução satisfatória do termo "geflügelte Worte” em português. Para tanto, faz-se necessário primeiramente descrever este termo, que designa um tipo muito específico de fraseologia na lingüística alemã. Trata-se originariamente de expressões e citações de origem bíblica, literária ou histórica

\footnotetext{
${ }^{1}$ Professora Doutora da Área de Alemão/FFLCH/ Universidade São Paulo. E-Mail: reichmann@usp.br
} 
conhecidas por uma grande parte dos falantes nativos e que foram incorporadas à língua alemã como fraseologias independentes. O termo foi cunhado pela coletânea mais conhecida de citações alemãs, publicada por Georg BÜCHMANN em 1864. Geflügelte Worte, palavras aladas, ${ }^{2}$ é o termo usado na Odisséia e na Ilíada de Homero (nas traduções alemãs de Friedrich Leopold Graf zu Stolberg e de Johann Heinrich Voß) para designar palavras que voam rapidamente, como se tivessem asas, da boca do falante ao ouvido do interlocutor. ${ }^{3}$ Büchmann considerou que essa expressão de Homero seria adequada para designar citações corriqueiras e conhecidas e, portanto, complementaria bem o título da coletânea de citações que estava por editar (HOFMANN 2007: VIII). ${ }^{4}$ É importante notar que a coletânea Büchmann não reunia apenas citações de autores conceituados propriamente ditas, mas sim aquelas que são usadas com sentido figurado e independentemente do seu contexto original. Segundo o autor, seriam expressões de autoria conhecida que são usadas de forma corriqueira, à maneira de provérbios. $^{5}$

Hoje em dia, porém, entendem-se por "geflügelte Worte” adágios, frases feitas, expressões ou nomes, em qualquer idioma, que sejam conhecidos por grande parte dos falantes de uma nação e cuja origem histórica ou literária seja comprovada. Isso também engloba publicações, títulos de livros, músicas ou filmes, slogans publicitários ou citações de personalidades da atualidade, sempre e quando os falantes tiverem uma “noção de autoria” dessas expressões (cf. HOFMANN 2007: VIII, BURGER 1998: 45 e GARSKY 2008: 109). Neste conjunto são consideradas também palavras individuais (FLEISCHER et al. 2001: 111), como por exemplo "Gretchenfrage”. ${ }^{6}$ As "Geflügelte Worte”, portanto, estão situadas entre citações propriamente ditas e fraseologias (WIENEN no prelo e FLEISCHER et al. 2001: 111).

\footnotetext{
${ }^{2}$ Na tradução da Ilíada em português feita por Carlos Alberto Nunes, São Paulo, Ediouro, s. d.

3 "Homer wollte damit nur den unsichtbaren, eiligen Weg des gesprochenen Wortes zum Ohr des Hörenden bildhaft werden lassen.” (RUST/HAUPT 1961: X). Os mesmos autores comentam que "beschwingte Worte" poderia haver sido uma melhor tradução para essa expressão (ibid.).

${ }^{4}$ Título original completo: “Geflügelte Worte. Der Citatenschatz des Deutschen Volks” (Hofmann 2007: VII).

5 “'Geflügelte Worte' nenne ich solche Worte, welche, von nachweisbaren Verfassern ausgegangen, allgemein bekannt geworden sind und allgemein wie Sprichwörter angewendet werden” (BÜCHMANN 1874 apud RUST/HAUPT 1961: XI)

6 “Mit diesem Ausdruck bezeichnet man eine unangenehme, oft peinliche und zugleich für eine bestimmte Entscheidung wesentliche Frage in einer schwierigen Situation. Es kann auch die Frage nach jemandes Religion oder politischer Überzeugung gemeint sein. (...) [Die Frage] wird - meist in der leicht abgewandelten Form “Wie hältst du's mit der Religion?” - zitiert, um auf ein wesentliches, entscheidendes, oft heikles Problem hinzuweisen und jemanden zu einer klaren Stellungnahme in der betreffenden Sache aufzufordern. (DUDEN 1993: 187-188). Termo traduzido como "pergunta crucial, pergunta decisiva” no Dicionário Porto Editora (1985).
} 
As expressões geralmente apresentam alguma característica marcante no plano lingüístico (concisão, rima, ritmo etc.) ou no plano do conteúdo (por exemplo, por formular algum pensamento original ou alguma verdade universal ou uma filosofia, semelhante a um aforismo). Tais expressões apresentam uma relação intrínseca com a cultura de uma sociedade e com o momento histórico, tanto é que, por exemplo, os editores do "Grande Büchmann” (nome dado à atualização da obra original) de 1961 decidiram remover citações e provérbios de cunho nacional-socialista (RUST/HAUPT 1961: VII).

Vale ressaltar ainda que o uso de citações e de frases célebres era particularmente freqüente no século XIX quando do processo de construção da identidade cultural após a fundação do Império Alemão. Frases célebres eram ainda citadas muitas vezes com o fim de simular uma formação clássica inexistente naquele que as usava (SELBMAnN 2005: 19-21 e HofmAnN 2007: VIII). Atualmente, tais expressões são usadas com muita freqüência como recurso retórico na mídia e na publicidade, incluindo não raro referências a citações e títulos de obras e filmes atuais. Curiosamente, até o próprio nome Büchmann acabou se tornando uma metonímia para designar uma pessoa que cita com freqüência (“ein wandelnder Büchmann” em analogia a "ein wandelndes Lexikon” [um dicionário ambulante]) e inspirou títulos de outras obras como Der rote Büchmann, Unbeflügelte Worte, zugleich Ergänzungen zum Büchmann, Der feldgraue Büchmann, Wo der Büchmann aufhört (BÜCHMANN 2007: 455-456).

Um outro aspecto curioso das "geflügelte Worte" são suas transformações e influências recíprocas. A frase célebre do Fausto "Im Anfang war die Tat" encontra a sua inspiração na frase bíblica "Im Anfang war das Wort” (BÜCHMANN 2007: 52) e a frase célebre de Bismarck “Was kannst du armer Teufel geben” é uma alteração da também frase célebre do Fausto “Was willst du armer Teufel geben?” (BÜCHMANN 2007: 132).

Após a descrição acima, nota-se que a expressão “geflügelte Worte” dificilmente encontra uma equivalência plena nas categorias de fraseologias da lingüística portuguesa: frases feitas, ditados, dizeres, anexins, provérbios, adágios, expressões idiomáticas, citações, sentenças - todas encerram conotações e fenômenos lingüísticos um pouco diferentes (cf. RÓNAI 1987: 27 e RÓNAI 1986: VIII-IX). Segundo a primeira definição de Büchmann, a expressão “geflügelte Worte” poderia talvez ser traduzida 
como “sentenças notáveis” ou como “frases célebres”. Porém, nenhuma dessas expressões englobam necessariamente as noções de metáfora, expressão idiomática e/ou citação de obras ou personalidades da atualidade, contidas no conceito de "geflügelte Worte”.

Para ilustrar o complexo desafio que a questão das “geflügelte Worte” representa ao tradutor, analisaremos exemplarmente - usando a ocasião também para fazer nossa pequena homenagem ao bicentenário da publicação do primeiro Fausto de Goethe algumas frases célebres desta obra magna da literatura alemã. Chamaremos a atenção para a complexidade estrutural e semântica de tais frases e as dificuldades de tradução que elas apresentam, bem como para a variedade do uso retórico dessas frases na atual linguagem publicitária e midiática na Alemanha. Antes disso, porém, recapitularemos primeiramente alguns aspectos relevantes para uma devida contextualização da tradução das obras de Goethe, após o que trataremos dos exemplos concretos das frases célebres e de sua tradução.

\section{Traduções de obras de Goethe}

A tradução exerce um papel fundamental na recepção de obras em outras culturas e no intercâmbio entre as literaturas. Goethe inclusive considerava que a tradução podia dar nova vida a uma obra, depois que esta foi de certa forma desgastada na sua língua original, levando a uma verdadeira metamorfose da obra. Fez tal comentário em relação às traduções de Hermann e Dorotéia em latim e do Fausto em francês, na tradução de Nerval (BERMAN 1995: 106-107). O contato entre as culturas é considerado um enriquecimento. Goethe vê, por exemplo, no contato com a cultura francesa (considerada antagônica à alemã) do início do séc. XIX uma possibilidade de cada cultura procurar na outra aquilo que lhe falta e que lhe é oposto. Desta maneira, os alemães poderiam aprender com o rigor formal dos franceses e a influência alemã poderia levar os franceses a se libertarem das regras estreitas do classicismo francês (BERMAN 1995: 101).

Diante disso, será útil uma breve apresentação das primeiras traduções de obras de Goethe em inglês e francês, bem como do percurso das traduções do Fausto em português, das quais tiraremos os exemplos para análise. 


\subsection{Traduções francesas de obras de Goethe}

A influência de Goethe na França começou com várias traduções do Werther. Entre 1776 e 1797, a obra foi traduzida quinze vezes e tornou-se a leitura preferida de toda uma geração. Em 1800, foi lançada a tradução francesa de Hermann e Dorotéia em prosa de Bitaubé. Dois anos mais tarde saíram duas traduções de Wilhelm Meister, em 1810 Afinidades eletivas e 1823 Poesia e Verdade. Mme. de Staël publicou comentários e alguns extratos do Fausto em 1813 e Fréderic-Albert Stapfer publicou as obras dramáticas de J. W. Goethe (4 volumes, 1821-1825) contendo Götz von Berlichingen, Egmont, Ifigênia na Táurida, Torquato Tasso e Fausto. Paralelamente à tradução de Stapfer, Sainte-Aulaire também lançou sua tradução do Fausto, porém é considerada inferior à de Stapfer. ${ }^{7}$ O próprio Goethe acabou dando mais valor à tradução do Fausto de Gérard de Nerval de 1828: Disse a Eckermann em 1830 que já não queria mais ler o Fausto em alemão e que na tradução francesa tudo lhe parecia novamente cheio de vida, novo e inteligente (HOFFMEISTER 1984: 94).

\subsection{Traduções inglesas de obras de Goethe}

A influência de Goethe na Inglaterra sucedeu parcialmente através das versões francesas. A obra de Mme. de Staël De l'Allemagne (1813) foi publicada em inglês no mesmo ano e teve grande repercussão na Inglaterra. A primeira tradução de uma obra de Goethe para o inglês (Werther) foi feita a partir da versão francesa em 1779, depois seguiram outras traduções diretamente a partir do alemão: Werther (1786), Os irmãos (1792), Ifigênia na Táurida (1793), Clavigo (1798), Götz von Berlichingen (1799), Hermann e Dorotéia (1801). Outras obras só foram traduzidas vinte ou trinta anos mais tarde, como uma tradução parcial do primeiro Fausto em 1823 e uma tradução completa do Fausto em prosa em 1833, Poesia e Verdade em 1823 (novamente a partir do francês), Os anos de aprendizagem de Wilhelm Meister em 1824 etc. (HofFMEISTER 1984: 56).

\subsection{Traduções portuguesas do Fausto}

O português Agostinho D’Ornellas foi o primeiro tradutor do Fausto para o

\footnotetext{
7 “Der erste Übersetzer, Sainte-Aulaire, der noch mit klassizistischer Befangenheit an den Faust herangegangen war und manche Szene unterdrückt hatte, wurde bald von Albert Stapfer ausgestochen, der sich getreu an das Original gehalten und lyrische Einlagen in französische Verse verwandelt hatte. Goethe hat die Güte dieser Übersetzung mehrfach anerkannt (...)” (HOFFMEISTER 1984: 82).
} 
português: em 1867 traduziu a primeira e em 1873 a segunda parte do Fausto (MAZZARI 2007: 18). Sua tradução gerou muita polêmica e foi revisada em 1953 por Paulo Quintela (HouAISs 2002: 19). ${ }^{8}$ Desde a tradução do Fausto de D’Ornellas, iniciou-se, também em Portugal, a recepção de Goethe. Seguiu-lhe Antônio Feliciano de Castilho, também português, que verteu o primeiro Fausto em 1872 (em verso) para o português, provavelmente baseando-se em versões francesas.

No Brasil, Gustavo Barroso (pseudônimo: João do Norte) verteu em prosa um texto do Fausto em 1920. Seguiu-se em 1964 a tradução de Antenor Nascentes e José Júlio de Sousa, em prosa e verso. Em 1968, Sílvio Meira publicou uma tradução da primeira parte, com o compromisso de publicar a segunda parte. Jenny Klabin Segall, esposa do famoso pintor Lasar Segall, traduziu a primeira parte em 1943 e a segunda parte até o ano em que morreu, em 1967 (cf. HouAIss 2002; 18-19). A mais nova tradução do Fausto de João Barrento (Portugal) data de $1999 .^{9}$

\subsection{Fausto e a tradução}

A complexidade do ato tradutório é tematizada pelo próprio Fausto no célebre “monólogo da tradução", reproduzido a seguir, quando o personagem se propõe verter o Evangelho de S. João para o alemão.

Mich drängt's, den Grundtext aufzuschlagen, Mit redlichem Gefühl einmal

Das heilige Original

In mein geliebtes Deutsch zu übertragen. Geschrieben steht: “Im Anfang war das Wort”! Hier stock’ ich schon! Wer hilft mir weiter fort? Ich kann das Wort so hoch unmöglich schätzen, Ich muß es anders übersetzen, Wenn ich vom Geiste recht erleuchtet bin. Geschrieben steht: Im Anfang war der Sinn. Bedenke wohl die erste Zeile, Daß deine Feder sich nicht übereile! Ist es der Sinn, der alles wirkt und schafft? Es sollte stehn: Im Anfang war die Kraft! Doch, auch indem ich dieses niederschreibe, Schon warnt mich was, daß ich dabei nicht bleibe. Mir hilft der Geist! Auf einmal seh’ ich Rat Und schreibe getrost: Im Anfang war die Tat!

\footnotetext{
${ }^{8}$ Veja-se o prefácio do tradutor D’Ornellas (2008) com comentários sobre a sua tradução.

${ }^{9}$ Veja-se também Mazzari (2007: 17-21) para mais comentários sobre as traduções portuguesas do Fausto.
}

\begin{abstract}
Almejo abrir o básico texto E verter o sagrado Original, Com sentimento reverente e honesto Em meu amado idioma natal. Escrito está: "Era no início o Verbo!” Começo apenas, e já me exacerbo! Como hei de ao verbo dar tão alto apreço? De outra interpretação careço; Se o espírito me deixa esclarecido, Escrito está: No início era o Sentido! Pesa a linha inicial com calma plena, Não se apressure a tua pena! É o sentido então, que tudo opera e cria? Deverá opor! No início era a Energia! Mas, já, enquanto assim o retifico, Diz-me algo que tampouco nisso fico. Do espírito me vale a direção, E escrevo em paz: Era no início a Ação!
\end{abstract} (Klabin Segall 1970: 68)

Abrir o arquitexto é uma tentação, Para, com sentir puro e leal, 
Das heilige Original

In mein geliebtes Deutsch zu übertragen. Geschrieben steht: “Im Anfang war das Wort”! Hier stock' ich schon! Wer hilft mir weiter fort? Ich kann das Wort so hoch unmöglich schätzen, Ich muß es anders übersetzen, Wenn ich vom Geiste recht erleuchtet bin. Geschrieben steht: Im Anfang war der Sinn. Bedenke wohl die erste Zeile, Daß deine Feder sich nicht übereile! Ist es der Sinn, der alles wirkt und schafft? Es sollte stehn: Im Anfang war die Kraft! Doch, auch indem ich dieses niederschreibe, Schon warnt mich was, daß ich dabei nicht bleibe. Mir hilft der Geist! Auf einmal seh’ ich Rat Und schreibe getrost: Im Anfang war die Tat!
Verter o sagrado original

No meu tão amado idioma alemão.

« Ao princípio era o Verbo! », é o que está escrito

Quem me ajuda? Logo aqui hesito!

Tanto não vale o verbo. Não,

Outra vai ter de ser a tradução,

Se bem me inspira o Espírito. Atento

E leio: «Ao princípio era o Pensamento. »

Esta linha tem de ser bem pensada,

Para que a pena não corra apressada!

É o Pensamento que tudo move e cria?

Certo é: « Ao princípio era a Energia! »

Mas agora que esta versão escrevi,

Algo me avisa já para não parar aí.

Vale-me o Espírito, já vejo a solução,

E escrevo, confiante: «Ao princípio era a Acção! » (BARRENTO 2003: 84)

Estes versos representam as diferentes fases e os processos criativos do ato de traduzir descritos em KußMAUL (2007: 79): “Präparation”, “Inkubation”, “Illumination” e “Evaluation”. Tais fases não ocorrem numa seqüência linear, muito pelo contrário: constituem uma progressão dinâmica com antecipacões, ponderações sobre as diferentes opções e alterações de versões anteriores. Neste episódio Fausto faz uma interpretação nova de um trecho do texto sagrado e procura uma primeira tradução intuitiva que critica e descarta em seguida. Depois de várias tentativas, elabora a sua versão final que acaba sendo uma alteração em relação ao original (KUßMAUL 2007: 80).

Também o tradutor Barrento se refere a este episódio do Fausto para descrever e fundamentar os princípios norteadores da sua tradução. Ele parte do princípio da tradutibilidade e acredita nas potencialidades da tradução em geral e da tradução de textos poéticos em especial. Para Barrento, a tradução é um ato carregado de boas intenções, porém com resultados sempre imprevisíveis. Descreve a tradução como "um processo de leitura rigorosa e de escrita aproximativa” (BARRENTO 2003: 21), o que equivale a um ato de interpretação ativa. Tomando como exemplo a palavra "verbo", Barrento afirma que a palavra poética "nunca se reduz ao mero conceito cristalizado" (ibid: 22) e ressalta que se traduzem palavras e discursos animados em determinados contextos temporais, locais e subjetivos. Ele considera que os quatro conceitos mencionados no monólogo (palavra, sentido, força/energia e ação) são representativos para uma concepção da tradução como um ato criativo (ibid: 23). Tais reflexões são 
fundamentais para a análise das diferentes traduções no próximo item. ${ }^{10}$

\section{Frases célebres do Fausto}

Neste item serão apresentadas três frases célebres do Fausto, muito presentes na língua alemã, a fim de se ilustrar a riqueza lingüística e semântica das mesmas. As diferentes traduções portuguesas permitem-nos estabelecer uma comparação em termos de micro-estrutura e comentar alguns aspectos da tradução. Importante é notar que não se trata aqui de uma avaliação da qualidade da tradução, pois para tanto seria necessário analisar os aspectos lingüísticos e poéticos na sua totalidade bem como os critérios de invariabilidade estabelecidos por cada tradutor.

\subsection{Da steh' ich nun, ich armer Tor}

Vejamos algumas traduções dos famosos versos “Da steh' ich nun, ich armer Tor! / Und bin so klug als wie zuvor", ditos por Fausto na cena "Nacht”, em que o personagem reconhece os limites da sua ciência e alimenta o desejo do saber. O início do verso inclusive faz lembrar a frase de suposta autoria de Lutero "Hier stehe ich! Ich kann nicht anders.” (BÜCHMANN 2007: 424)

354 Hab nun, ach, die Philosophei,

355 Medizin und Juristerei,

356 Und leider auch die Theologie

357 Durchaus studiert mit heißer Müh.

358 Da steh ich nun, ich armer Tor,

359 Und bin so klug, als wie zuvor.
Filosofia, Leis e Medicina,

Teologia 'té, com pena o digo,

Tudo, tudo estudei com vivo empenho!

E eis-me aqui agora, pobre tolo,

Tão sábio como dantes!

Ao cabo de escrutar co’o mais ansioso estudo

filosofia, e foro, e medicina, e tudo

até a teologia... encontro-me qual dantes;

em nada me risquei do rol dos ignorantes.

- Tenho estudado até agora, ah! Filosofia, Jurisprudência, Medicina e por desgraça também

Teologia, profundamente e com ardente esfôrço.

Pobre louco, continuo na mesma! E sou tão sábio como dantes;

Estudei com ardor tanta Filosofia,

Direito e Medicina,

E infelizmente até muita Teologia,

E tudo investiguei com esfôrço e desciplina

E assim me encontro, eu, qual pobre tolo, agora,

Tão sábio e culto quanto acaso fôra outrora!

Ai de mim! da filosofia,
(D'ORNELLAS

2008: 33)

(CASTILHO

1948: 27)

(NASCENTES

1964: 17)

(MEIRA 1968:

31)

(KLABIN

\footnotetext{
${ }^{10}$ Veja-se também AzEnHA (2006 : 53-56) sobre os “modos de traduzir” que Goethe descreveu nas "Notas ao divã”.
} 
Medicina, jurisprudência,

SEGALL 1970:

E, mísero eu! da teologia,

O estudo fiz, com máxima insistência.

Pobre simplório, aqui estou

E sábio como dantes sou!

Aqui estou eu: Filosofia,

BARRENTO

Medicina e Jurisprudência,

2003: 50)

E para meu mal até Teologia

Estudei a fundo, com paciência.

E reconheço, pobre diabo,

Que sei o mesmo, ao fim e ao cabo!

Quanto à forma, nenhuma das traduções acima oferece a concisão do octassílabo de Goethe, que tornam o verso particularmente marcante no alemão. A rima foi reproduzida por Castilho, Meira, Klabin Segall e Barrento. Ressalte-se, porém, a tradução de Barrento, que com o seu decassílabo imita muito bem o ritmo do original.

\subsection{Zwei Seelen wohnen, ach! in meiner Brust}

Esta frase célebre do Fausto, que demonstra a sua luta interior entre a busca do prazer e a virtude divina, foi traduzida em português das seguintes formas:

1110 Du bist dir nur des einen Triebs bewußt;

1111 O lerne nie den andern kennen!

1112 Zwei Seelen wohnen, ach! in meiner

1113 Brust,

1114 Die eine will sich von der andern trennen;

1115 Die eine hält, in derber Liebeslust,

1116 Sich an die Welt mit klammernden Organen;

1117 Die andre hebt gewaltsam sich vom Dunst $\mathrm{Zu}$ den Gefilden hoher Ahnen.
Só duma aspiração tens consciência;

Oh, não queiras jamais sentir a outra!

Duas almas habitam no meu peito,

Uma da outra separar-se anseiam:

Uma com órgãos materiais se aferra

Amorosa e ardente ao mundo físico;

Outra quer insofrida remontar-se

De sua excelsa origem às alturas.

Falas assim porque só tens uma aflição, Não procures jamais as outras desvendar!

No meu corpo há duas almas em competição,

Anseia cada qual da outra se apartar.

Uma rude me arrasta aos prazeres da terra

E se apega a êste mundo, anseios redobrados;

Aspira à vida eterna a seus antepassados.

Tiveste consciência de um impulso, apenas,

oh! nunca aprendas a conhecer o outro! Duas

almas, ai de mim!, moram em meu peito,

uma quer apartar-se da outra; uma prende-se ao mundo em violento prazer de amor, com órgãos que seguram como garras; a outra alça-se fortemente do pó para as moradas dos velhos antepassados.

Sim. Por enquanto

não aspiras a mais. Conheces uma
(D'ORNELLAS

2008: 56)

(CASTILHO

1948: 60)

(NASCENTES

1964: 39)

(MEIRA 1968:

72 ) 
das duas sedes d'alma; o céu te livre de sentires a outra.

\section{Albergo dentro}

dois espíritos, dois; forcejam ambos por se fugir: - um deles, voluptuoso, abraça a terra; os órgãos o segundam; o arraigam nela; - o outro, desdenhando este mundo, este pó, se evade em busca das regiões que nossos pais habitam. Apenas tens consciência de um anseio; A conhecer o outro, oh, nunca aprendas! Vivem-me duas almas, ah! no seio, Querem trilhar em tudo opostas sendas; Uma se agarra, com sensual enleio É órgãos de ferro, ao mundo e à matéria; A outra, soltando à fôrça o térreo freio, De nobres manes busca a plaga etérea. Não conheces mais que uma aspiração, Da outra melhor é nada saber!

(KLABIN SEGALL 1970: 48)

No plano métrico, nenhuma das traduções reproduz o decassílabo de Goethe. Quanto aos demais aspectos, a ênfase expressa pela interjeição “ach!” é reproduzida por Nascentes e Klabin Segall, também através de uma interjeição, e por Meira, que recorre à repetição da palavra “dois”. Castilho tenta expressar a gravidade desta luta interior através do termo “competição", enquanto a versão de Barrento perde um pouco da expressividade do original.

\subsection{Schall und Rauch}

Outra frase célebre famosa é a metáfora com que Fausto responde a pergunta de Margarida sobre a religião: 
Não tenho nome algum para isso. Sentimento é tudo; nome é ruído e fumaça, que enevoa o brilho celeste.

Eu não dou nome algum,

MEIRA (1968:

Não encontro nenhum.

Assim! o sentimento é tudo para mim.

O nome é apenas som, esvai-se em seus vapôres,

A encobrir-nos do olhar o céu com seus fulgores!

Não tenho nome para tal!

KLABIN

O sentimento é tudo;

SEGALL (1970:

Nome é vapor e som,

Nublando ardor celeste

Para isso não tenho nome

Nome é rumor e fumo

Que tolda o brilho dos céus

A aliteração do original com a vogal tônica “a” (Nâme ist Schall und Rauch) pode ser imitada no português através da repetição da vogal tônica “o”, o que é realizado desta forma por D’Ornellas, Meira, Klabin Segall e Barrento: O nome é apenas som, esvai-se em seus vapô̂res; Nome é vapor e som; Nome é rumor e fumo. Mas somente as traduções de Klabin Segall e Barrento apresentam a mesma forma concisa do original.

\section{Tradução das frases célebres}

A literatura sobre frases célebres em alemão é vasta, mas não poderá ser tratada exaustivamente neste trabalho. Preferimos mencionar aqueles que tratam de fraseologias e frases célebres alteradas, como GARSKI (2008), que enumera uma grande quantidade de exemplos da língua da mídia alemã atual, como por exemplo “Der mit dem Wort tanzt” (em referência ao filme "Der mit dem Wolf tanzt” [Dança com lobos]) ou "Wir sind dann mal weg” (em referência ao título do bestseller "Ich bin dann mal weg” de Hape Kerkeling), sendo que o jogo de palavras só é entendido se for relacionado ao título ou à citação original (GARSKI 2008: 105-107).

Há pouco material sobre a tradução de frases célebres (ou frases célebres modificadas). Ressaltamos os ensaios de WiEnEN (2007) e WiEnEN (no prelo) que estudam este tema para o par lingüístico alemão-francês. ${ }^{11}$ Os trabalhos da lingüística

\footnotetext{
${ }^{11}$ Agradeço à colega Ursula Wienen pelos impulsos e pelas discussões acerca deste tema.
} 
contrastiva e da tradutologia geralmente se referem a metáforas (p. ex. KOLLER 2004: 254-258, SCHÄFFnER 2005) ou fraseologias (p. ex. DoRnBusch 1989, CAMARGO 1991, ETtinger/NunEs 2006, SchemAnN/DiAs-SCHEMANN 1980, ALBRECHT 2005: 118-120 e KOLLER 2007) e podem ser parcialmente aplicadas à tradução de frases célebres devido à sua metaforicidade e à sua semelhança com fraseologias.

Em relação às fraseologias, ALBRECHT (2005: 118) ressalta o fato de se tratar de sintagmas pré-existentes, cujo significado deve ser traduzido como um todo, seja com uma fraseologia ou outro recurso lingüístico (metáfora, paráfrase etc.), sem se recorrer a uma tradução literal. Os jogos de palavras com fraseologias também representam um recurso estilístico freqüente, como, por exemplo, em contextos que permitem uma leitura tanto conotativa como denotativa: “Zwanzig Jahre war ich mit dem langweiligen Kerl verheiratet, und jeden Abend saß er im Lehnstuhl vor der Glotze. Da hab ich ihn eben sitzen lassen” (ibid: 119). O mesmo acontece com frases célebres que são usadas, com ou sem alterações, como locuções idiomáticas. As alterações permitem introduzir um aspecto novo, muitas vezes jocoso ou irônico, ao mesmo tempo que mantêm a alusão à forma e ao significado originais (cf. WIENEN no prelo).

Neste contexto, Albrecht ressalta ainda a dificuldade de reconhecer certas locuções ou citações alteradas em textos e a importância de pesquisar o teor exato do original quando é feita uma tradução para o idioma da citação original: "Nichts ist peinlicher als eine unbeholfene Rückübersetzung eines Zitats, eines 'geflügelten Wortes’ in die Sprache, aus der es stammt.” (ibid: 71). Albrecht (2005: 118-120) e KOLLER (2007) comentam dificuldades e soluções possíveis da tradução de fraseologias no seu respectivo contexto.

Em termos metodológicos, poder-se-ia supor que, no processo de tradução, podemos lidar com as frases célebres tal como lidamos com citações. Neste caso, recorrer-se-ia, como geralmente se faz, a traduções já existentes das obras. Mas as frases célebres representam um especial desafio para a tradução. A começar pelo fato de que existem várias traduções diferentes às quais recorrer. Quais critérios aplicaríamos então para decidir qual tradução usar? Independentemente do valor de cada uma dessas traduções como um todo, as traduções dos trechos que acabaram se tornando frases célebres podem ter chegado a resultados mais ou menos adequados segundo certos critérios lingüísticos, como, por exemplo, concisão, idiomaticidade, ritmo, rima, figura de linguagem etc. Outro aspecto a ser levado em conta é que a frase célebre original é 
muito mais difundida na cultura-fonte do que a frase célebre traduzida na cultura-alvo. Na cultura de partida a referência a tais frases é muito mais evidente do que na cultura de chegada. Além disso, as frases célebres geralmente apresentam um nível metafórico nem sempre presente nas traduções.

Um critério para avaliar até que ponto uma citação é conhecida na outra cultura seria a consulta de coletâneas de citações que contenham citações estrangeiras - no caso do português, mencione-se como por exemplo o dicionário de RÓNAI (1986). Esta obra apresenta 126 citações de Goethe, das quais 28 do Fausto, todas baseadas na tradução de Klabin Segall. O autor selecionou as citações segundo o critério da freqüência: “Um dicionário de citações visa, antes de mais nada, a reproduzir, em seu texto exato, frases freqüentemente citadas” (RóNAI 1986: VIII). Porém, muitas sentenças do Fausto escolhidas por Rónai não são aquelas que foram incorporadas à fraseologia alemã. Partimos da hipótese de que Rónai escolheu as citações prioritariamente pelo seu conteúdo, enquanto um dos critérios de seleção de Büchmann foi justamente uma forma lingüística marcante, seja pelo ritmo, pela rima, pela brevidade ou pela originalidade, o que nem sempre foi ou pôde ser reproduzido da mesma forma na tradução.

Vejamos alguns exemplos do emprego de frases célebres em títulos de textos da atualidade alemã. O primeiro é o título de uma resenha publicada no jornal FAZ sobre o livro "Mandelkern” de Lea Singer: "Da steh ich nun, ich armes Gör”. 12 O título faz referência à protagonista do livro, a neuróloga Grace Edler, que é uma figura fáustica feminina e está no seu laboratório dois dias antes do Natal planejando suicidar-se. Algumas adaptações possíveis das traduções seriam:

(01) E eis-me aqui agora, pobre tola (D’Ornellas)

(02) Encontro-me qual dantes; (Castilho, sem adaptação)

(03) Pobre louca, continuo na mesma! (Nascentes)

(04) E assim me encontro, eu, qual pobre tola, agora (Meira)

(05) Pobre simplória, aqui estou (Klabin Segall)

(06) E reconheço, pobre diabo (Barrento, sem adaptação)

A substituição da palavra “Tor” por “Gör” produz o efeito jocoso deste título, que apesar disto continua sendo reconhecível como a citação original do Fausto. As traduções de Castilho e Barrento não permitem uma adaptação semelhante, enquanto que as de D’Ornellas, Nascentes, Meira e Klabin Segall permitem a alteração do gênero

\footnotetext{
${ }^{12}$ Texto de Sabine Doering. Frankfurter Allgemeine Zeitung / Sonntagszeitung de 19/5/2008, p.34.
} 
(louca, tola, simplória) e assim imitar o efeito do original.

O segundo exemplo é o título de um artigo sobre o $80^{\circ}$ aniversário do escritor e tradutor judeu Georges-Arthur Goldschmidt: “Zwei Seelen wohnen, ach! in seiner Brust”. ${ }^{13} \mathrm{O}$ título alude ao fato de que Goldschmitdt, que foi salvo da perseguição nazista por ter sido mandado pelos seus pais para o sul da França, teria afinidade com ambas as culturas, a alemã e a francesa. Vejamos algumas adaptações possíveis do título do artigo:

(07) Duas almas habitam no seu peito (D’Ornellas)

(08) No seu corpo há duas almas em competição (Castilho)

(09) Duas almas, ai dele! , moram em seu peito (Nascentes)

(10) Alberga dentro dois espíritos, dois (Meira)

(11) Vivem-lhe duas almas, ah! no seio (Klabin Segall)

(12) Duas almas tem em seu coração (Barrento)

Apesar de essa citação do Fausto não ser tão conhecida no mundo lusófono (por exemplo não consta no dicionário de citações de RóNAI [1986]), todas as adaptações acima evocam um estilo poético, reproduzindo pelo menos parcialmente o efeito do original.

O último exemplo é um texto sobre a grande controvérsia provocada pela lei introduzida recentemente na Alemanha que proíbe fumar em restaurantes e bares. $\mathrm{O}$ título de um artigo sobre esta discussão acirrada era: Alles nur Schall und Rauch? Das Rauchverbot sorgt für Wirbel ${ }^{14}$. Neste caso, brinca-se com a dualidade dos sentidos: "Rauch" refere-se literalmente ao fumo sobre o qual versa o artigo e "Schall und Rauch” é usado metaforicamente, no sentido de ser algo de pouca relevância. Recorrendo às traduções acima mencionadas e na mesma seqüência, teríamos as seguintes possibilidades:

(13) O nome é rumor vão, o nome é fumo? A proibição do fumo gera polêmica. (D’Ornellas)

(14) Nome é fumo? A proibição do fumo gera polêmica. (Castilho)

(15) Nome é ruído e fumaça? A proibição do fumo gera polêmica. (Nascentes)

(16) O nome é apenas som, esvai-se em seus vapôres? A proibição do fumo gera polêmica. (Meira)

(17) Só vapor e som? A proibição do fumo gera polêmica. (Klabin Segall)

(18) Só rumor e fumo? A proibição do fumo gera polêmica. (Barrento)

\footnotetext{
13 "Buchreport" de 29/4/2008 (http://www.buchreport.de/).

${ }^{14}$ In: Revista Champus 6/2007, p. 26.
} 
As adaptações baseadas nas traduções de D’Ornellas e Meira são demasiado longas e pouco idiomáticas. Além disso, no caso de Meira perde-se a referência ao fumo devido à imagem usada do "vapor”, o que também é o caso da tradução de Klabin Segall. Já as traduções de Castilho, Nascentes e Barrento apresentam mais possibilidades de realizar uma adaptação desta frase célebre no contexto referido. A única tradução que realmente permite estabelecer uma dualidade de significados semelhante ao original é a de Barrento, porque além de o "fumo" remeter diretamente ao tema do vício, o “rumor" pode ser entendido como uma agitação passageira e portanto insignificante, gerando assim uma analogia com o significado metafórico de “Schall und Rauch”. Porém, sua tradução é, dentre todas as aqui mencionadas, a mais recente e talvez por tal motivo ainda não tenha tido tempo de se fazer tão conhecida no mundo lusófono atual.

\section{Conclusão}

A tradução de frases célebres e suas variantes nos textos apresentam ao nosso ver um grau de dificuldade ainda maior do que a tradução de metáforas, dado que não somente deve ser reproduzido o nível metafórico, mas também a forma (rima, ritmo, etc.). Será o trabalho de cada tradutor usar a sua competência “empática” (KOHLMAYER 2004: 11ss.) e seus conhecimentos lingüísticos, culturais, formais e literários para tentar encontrar uma solução que produza efeitos semelhantes na cultura-alvo. Poderá, por exemplo, recorrer a citações totalmente diferentes da própria cultura-alvo que expressem um conteúdo semelhante.

Uma possibilidade para o público brasileiro seria substituir o primeiro exemplo (“Da steh ich nun, ich armes Gör”) por um verso do famoso poema do Carlos Drummond de Andrade "No meio do caminho", com ou sem alterações: "No meio do caminho tinha uma pedra” ou "No meio do caminho dela tinha uma pedra”. O intuito desta adaptação seria encontrar uma citação consagrada e reproduzir o efeito do reconhecimento de uma citação que contenha uma metáfora próxima. Neste caso, a frase célebre alterada é usada como recurso para demonstrar a falta de perspectivas para a solução de um problema. Trata-se de estabelecer uma analogia com uma citação, conhecida pelo leitor brasileiro, a qual possa simbolizar um problema. Ao nosso ver, os exemplos comentados neste trabalho deixam claro que a tradução de textos com frases 
clélebres alteradas demanda muita criatividade por parte do tradutor, impelindo-o a um ato de recriação ou de formação de analogias que imite os efeitos do original.

Será apropriado concluir nossas considerações com uma reflexão feita por Umberto Eco acerca das expressões “texto-fonte” e “texto-alvo” (ou analogamente “cultura-fonte” e “cultura-alvo”). O termo “alvo” transmite a idéia de que existe só um alvo a ser atingido. Em relação a textos literários o autor considera mais adequado falar de "texto-fonte” e "texto-foz" (no lugar de “alvo") (termo sugerido por Federico Montanari) para expressar a abertura à interpretação na tradução. Segundo ele, o termo "foz" remete a um campo semântico que permite refletir sobre as diferentes formas da foz. Haveria aquela que se transforma em um grande delta, que tem a força de enriquecer o texto-fonte por levá-lo até um “mar” de intertextualidades. E haveria aquele tipo de foz cujo delta vai se separando em vários canais individuais, que levam muito menos água do que o rio original, mas que juntos acabam abrangendo uma área grande (ECO 2006: 230-231). Essa metáfora da foz usada por Eco é capaz de ilustrar muito bem o impacto de uma tradução na cultura de chegada e a importância do papel do tradutor nesse processo. De fato, o grande desafio que uma frase célebre, alterada ou não, impõe ao tradutor é justamente o de saber que tipo de foz ele deseja formar com sua tradução. ${ }^{15}$

\section{Referências bibliográficas}

ALBRECHT Jörn. Übersetzung und Linguistik. Tübingen, Narr, 2005.

AZENHA JR., João. Goethe e a tradução: a construção da identidade na dinâmica da diferença. In: Literatura e Sociedade ${ }^{\circ}$ 9. São Paulo, USP/FFLCH, 2006, 4459.

BARRENTO, João. Introdução. In: Goethe, Johann Wolfgang von, Fausto. Lisboa: Relógio D’Água Editores, 2003 [ $\left.{ }^{1} 1999\right], 17-23$.

BERMAn, Antoine. L'épreuve de l'étranger. Culture et traduction dans l'Allemagne romantique. Herder, Goethe, Schlegel, Novalis, Humboldt, Schleiermacher, Hölderlin. Paris, Gallimard, 1995.

BÜCHMAnN, Georg. Geflügelte Worte. Der Zitatenschatz des deutschen Volkes. Berlin: Haude \& Spenersche Verlagsbuchhandlung, ${ }^{30} 1961$.

\footnotetext{
${ }^{15}$ Agradeço aos pareceristas e à colega Beatriz Vasconcelos pelos valiosos comentários acerca deste trabalho.
} 
BÜCHMAnN, Georg. Geflügelte Worte. Der klassische Zitatenschatz. Bearbeitet und aktualisiert von Winfried Hofmann. München: Ullstein, 2007.

Burger, Harald. Phraseologie. Eine Einführung am Beispiel des Deutschen. Berlin: Erich Schmidt, 1998.

CAMARGo, Sidney. Fraseologia contrastiva alemão-português. In: Anais do II encontro de professores de línguas estrangeiras. Assis: UNESP/FCL, 1991, 108-112.

D’Ornellas, Agostinho Prefácio do tradutor. In: Goethe, Johann Wolfgang von Fausto. São Paulo: Martin Claret, ${ }^{2} 2008$ [1867], 11-14.

DoRnBusCH, Claudia Sybille. Ein Kapitel für sich - oder: Einmal die Wörter tanzen lassen. Redewendungen für den Fremdsprachenunterricht Deutsch. In: ProjektAPPA. Revista da Associação Paulista de Professores de Alemão. São Paulo: APPA, 1989, 76-91.

DudEn. Zitate und Aussprüche. Band 12. Mannheim: Dudenverlag, 1993.

Eco, Umberto. Quasi dasselbe mit anderen Worten. München: Carl Hanser, 2006.

EtTINGER, Stefan / Manuela NunEs. Portugiesische Redewendungen. Hamburg: Buske, 2006.

Fleischer, Wolfgang / Gerhard HeLbig / Gotthard LerChneR (eds.) Kleine Enzyklopädie Deutsche Sprache. Frankfurt/M.: Lang, 2001.

GARSKI, Rudolf. ,Der mit dem Wort tanzt' - Kreativer Gebrauch von Phraseologismen in Zeitungsüberschriften. In: Der Sprachdienst 3/2008. Herausgegeben von der Gesellschaft für deutsche Sprache. Wiesbaden: GfdS, 2008, 105-117.

GoETHE, Johann Wolfgang. Faust. Der Tragödie erster und zweiter Teil. Urfaust. Herausgegeben und kommentiert von Erich Trunz. München: Beck, 1999.

GoETHE, Johann Wolfgang. Fausto. Tradução de Jenny Klabin Segall. Prefácios de Erwin Theodor e Antônio Houaiss, posfácio de Sérgio Buarque de Holanda. Belo Horizonte: Editora Itatiaia, ${ }^{5} 2002$.

GoETHE, Johann Wolfgang. Fausto. Tradução, introdução e glossário de João Barrento. Lisboa: Relógio D’Água Editores, 2003 [ $\left.{ }^{1} 1999\right]$.

Goethe, Johann Wolfgang. Fausto. Tradução de Agostinho d'Ornellas. São Paulo: Martin Claret, ${ }^{2} 2008\left[{ }^{1} 1867 / 1873\right]$.

Goethe, Johann Wolfgang. Fausto. Uma tragédia. Segunda Parte. Tradução do original alemão de Jenny Klabin Segall. Apresentação, comentários e notas de Marcus Vinicius Mazzari. Edição bilíngüe. São Paulo: Editora 34, 2007 [ $\left.{ }^{1} 1967\right]$. 
HoffMeIster, Gerhart. Goethe und die europäische Romantik. München: Francke, 1984.

Hofmann, Winfried. Einleitung. In: BüChMANN, Georg: Geflügelte Worte. Der klassische Zitatenschatz. Bearbeitet und aktualisiert von Winfried Hofmann. München: Ullstein, 2007,.VII-IX.

HouAISs, Antônio. Prefácio. In: GoETHE, Johann Wolfgang, Fausto. Tradução de Jenny Klabin Segall. Belo Horizonte: Editora Itatiaia, ${ }^{5} 2002$, 15-24.

KOHLMAYER, Rainer. Einfühlungsvermögen - Von den menschlichen Grundlagen des Literaturübersetzens. In: KOHLMAYER, Rainer / Wolfgang PÖCKL (eds.), Literarisches und mediales Übersetzen. Aufsätze zu Theorie und Praxis einer gelehrten Kunst. Frankfurt/M.: Lang, 2004, 11-30.

KOLLER, Werner. Einführung in die Übersetzungswissenschaft. Wiebelsheim: Quelle \& Meyer, ${ }^{7} 2004$.

Koller, Werner. Probleme der Übersetzung von Phrasemen. In: BuRger, Harald, Dmitrij Dobrovol’skiJ, Peter KÜHn, Neal Norrick (eds.). Phraseologie Phraseology. Handbuch zur Sprach- und Kommunikationswissenschaft (HSK), Band 28.1., 2007, 605-613.

KußMAUL, Paul. Kreatives Übersetzen. Tübingen: Stauffenburg, ${ }^{2} 2007$

MAzZARI, Marcus Vinicius. A segunda parte do Fausto: 'esses gracejos muito sérios' do velho Goethe. In: GoETHE, Johann Wolfgang (2007 [ $\left.\left.{ }^{1} 1967\right]\right)$, Fausto. Uma tragédia. Segunda Parte. São Paulo: Editora 34, 2007, 7-27.

Porto Editora. Dicionário Porto Editora Alemão-Português. Porto: Porto Editora, 1985

RÓNAI, Paulo. Prefácio. In: MotA, Leonardo, Adagiário brasileiro. São Paulo: Edusp, 1987.

RónAI, Paulo. Dicionário universal Nova Fronteira de citações. Rio de Janeiro: Nova Fronteira, ${ }^{4} 1986$.

Rust, Werner / Gunther HAuPT. Vorwort. In: BüchmAnN, Georg, Geflügelte Worte. Der Zitatenschatz des deutschen Volkes. Berlin: Haude \& Spenersche Verlagsbuchhandlung, 1961, VI-XII.

SCHÄFFnER, Christina. Metaphern. In: SNELl-HoRnBy, Mary et al. (eds.), Handbuch Translation, Tübingen, Stauffenburg, 2005, 280-285.

Schemann, Hans / Luiza Schemann-Dias. Dicionário idiomático português-alemão. Portugiesisch-deutsche Idiomatik. Braga: Cruz / Hueber. 1980. 
Selbmann, Rolf. Deutsche Klassik - eine Rekonstruktion. In: SElbmann, Rolf (ed.), Deutsche Klassik. Epoche, Autoren, Werke. Darmstadt: Wissenschaftliche Buchgesellschaft. 2005, 7-34.

Wienen, Ursula. Voilà donc le noyau du barbet - Frases célebres del Fausto en sus traducciones al francés. In: ATAYAN, Vahram / Daniela PIRAZZINI / Laura SERGO / Gisela ThOme (eds.) Übersetzte Texte und Textsorten in der Romania. Frankfurt/M: Lang. P., 2007, 159-177.

WIENEN, Ursula (no prelo), “Ici je suis homme, ici j’ose l'être. Geflügelte Worte aus Goethes Faust in französischer Übersetzung”. In: Forum Junge Germantistik. 